\title{
Children, Mothers and the Criminal Justice System
}

\author{
Doret J. de Ruyter ${ }^{1}$, Sanne C. E. M. Hissel ${ }^{2} \&$ Catrien C. J. H. Bijleveld $^{2}$ \\ ${ }^{1}$ Department of Research and Theory in Education, VU University Amsterdam, the Netherlands \\ ${ }^{2}$ NSCR (Netherlands Institute for the Study of Crime and Law Enforcement) and VU University Amsterdam, the \\ Netherlands \\ Correspondence: Doret J. de Ruyter, Department of Research and Theory in Education, VU University \\ Amsterdam, De Boelelaan 1105, 1081 HV Amsterdam, The Netherlands. Tel: 31-20-598-8874. E-mail: \\ dj.de.ruyter@vu.nl
}

Received: May 3, 2013 Accepted: June 12, 2013 Online Published: July 19, 2013

doi:10.5539/res.v5n4p43 URL: http://dx.doi.org/10.5539/res.v5n4p43

\begin{abstract}
Every year, a substantial number of children are confronted with the detention of their mothers. Empirical research shows that the well-being of children is seriously affected by their mother's imprisonment, although no study has been able to assess whether detention of a mother as such causes long-term damage. This article defends the principle that mothers who are actively involved in raising children should not receive a prison sentence but an alternative punishment. The interests of children are a sufficient reason to prevent 'collateral damage' to their well-being - unless it is evident that continuing care is detrimental to the children or if the legal order or the interests of society and its citizens would be disproportionally threatened.
\end{abstract}

Keywords: imprisonment of mothers, alternative sentencing of mothers, children's interests, good enough parent

\section{Introduction}

Imprisonment of parents has a profound impact on their children. Parental detention disrupts children's lives and can cause grief, shame and stigma. Moreover, imprisonment of parents who are primary caregivers means that they can no longer exert their parental role and responsibility: Parents have to stop raising their children.

The number of children that are affected by the incarceration of their parents has increased substantially over the years due to the enormous rise in the number of detainees in Western countries (for instance, Tonry and Bijleveld, 2007; Scharff-Smith and Gampell, 2011). This rise has been steeper for mothers, who are more often than fathers the primary caregivers (Note 1) (Glaze \& Maruschak, 2010). Thus, children's care-giving arrangements tend to change substantially when mothers are imprisoned (Note 2) (see for instance Bloom, 1993; Fishman, 1983; Murray \& Farrington, 2008; Myers, Smarsh, Amlund-Hagen, \& Kennon, 1999; Schafer \& Dellinger, 1999; Tasca, Rodriguez, \& Zatz, 2011; Travis, 2005).

Parental detention can have a profound impact on the well-being of the children, as the next section will describe, and has been shown to relate to elevated levels of both internalizing and externalizing problem behavior. Children of prisoners have been shown to exhibit elevated levels of problem behavior well into adulthood, such as offending, at higher levels than children separated from a parent because of hospitalization or parental death (Murray \& Farrington, 2005), underlining the long-term impact associated with parental detention.

This article defends the principle that mothers who are actively involved in raising children should not receive a prison sentence but rather an alternative punishment, because of the harm that may be caused to the interests of their children. Our arguments will be built around mothers, but what we say applies mutatis mutandis to (the detention of) fathers (or grandparents) in case they are primary caregivers (Note 3). Stated differently, our primary consideration pertains to the needs of the child rather than the gender of the caregiver.

The justification of the alternative punishment principle draws on the interests of a third party that are unrelated to the criminal offence, i.e. the children of an offender. Both the principle and the justification require various types of arguments, such as legal, ethical and pedagogical arguments, as well as empirical, theoretical and normative arguments. This article will provide pedagogical arguments in defense of the claim that the interests of children are of such importance that they override the principle of equality before the law. Moreover, our contribution to the justification of the principle is theoretical and normative-ethical in nature although to evince 
that our theoretical castle is not built on sand, the next section will outline empirical research performed by others. We should note that we will not enter into a philosophical discussion about related legal topics such as individual and general deterrence, the grounds for mitigation in general or into the debate about prison abolitionism. These issues are highly important, but here we want to investigate the strength of a particular justification for differential treatment, which, it should be noted, is not the same as mitigation, of a specific group of offenders.

The theoretical and pedagogical perspective also means that we do not offer concrete solutions how the principle should be phrased in legal terms or carried out in practice, although we will reflect on some practical suggestions at the end. Nor do we analyze jurisdiction and jurisprudence to investigate courts' decisions in cases where mothers were facing a prison sentence or how their decisions have changed existing legal rules - in some countries judges as a standard procedure do give weight to children's interests in deciding on a sanction for their mothers. In this article, we defend a more radical principle - one that actually turns the legal standard upside down. We defend that claim that judges should begin with the presupposition that mothers who are actively involved in raising their children should be treated differently, as justified by the best interests of their children.

It is important to bear in mind that there is a difference between defending the principle of differential treatment of mothers and applying the principle in practice. In this article we are interested in discovering if there are sufficient reasons for justifying the principle. The application can lead to different conclusions in different cases. Thus, even if we are able to justify differential treatment of mothers on the basis of their children's interests, this does not necessarily lead to differential treatment of all mothers. For, it is possible that not only another legal rule or regulation overrides the principle of alternative sentencing of mothers, but also that the interests of children in a particular situation are not met by the principle. In philosophical terms, we defend a prima facie rule, not an absolute one.

In the next section we will describe the current evidence on the effect of mothers' detention on their children. Many of the data we provide come from the Netherlands, where an in-depth quantitative and qualitative study amongst detained mothers and their children was recently carried out that adds to former existing evidence mainly from the U.S. (Hissel, Bijleveld, \& Kruttschnitt, 2011). The third section describes and defends the principle of alternative sentencing on the basis of children's interests. Section four discusses arguments against our position and will show that these do not have sufficient force to change the principle we defend. In our concluding section we do not only reiterate our main point of view, but also sketch some of the possible practical consequences for the welfare system. We are cautious, however, in describing these implications, because this needs much more empirical research than is currently available.

\section{Detention of Mothers}

We aim to defend the claim that there are cases in which adults should not be detained, although their crime would justify such a sentence, because they are parents, in case of this study, mothers. Our defense for a special treatment of this group of persons is not based on their personal aspects or to circumstances related to the crime but on their special role and responsibilities for their children. In other words, our plea for a special treatment is not based on who they are or why they committed a crime, but on their position or role, which is in itself unrelated to their criminal act.

For our question it is particularly important to make a distinction between biological parents and caregivers. Normally, biological parents are also the caregivers and educators of their children. The majority of adults do not procreate just to bring a child to life, but they also want a close relationship with their children, look after them and be responsible for their upbringing. Parents are bestowed with rights to raise their children, which does not only serve their own interests, but of their children too, as we will further explore in the third section. However, there are also situations in which biological parents are not raising the child themselves. Due to divorce, voluntary or imposed residential or foster care of children, some children have biological parents as well as caregivers, who can be professionals or new parents as in the case of foster parents.

In terms of the sentencing of mothers, there are mothers who are caregivers of their children and those who are not. In both situations it is likely that children benefit from maintaining personal relations and therefore to have (frequent) contact with their mothers if they would be imprisoned. This maintenance of contact may allow for a different treatment of mothers whilst they are in prison. However, in situations in which children are actually being raised by their mother, which in the Netherlands (Ezinga \& Hissel, 2010) applied to 60\% of the imprisoned women, the impact of the imprisonment on the children's well-being is clearly much more profound. These children are not only separated from their biological parent, but also from their daily caregiver. This 
article focuses on this specific group of mothers, i.e. those mothers who were actively involved in raising their children up until their detention.

It seems quite obvious to suggest that the most powerful reason for treating mothers differently from other adults with respect to imprisonment is the possible detrimental effect on the interests of their children. However, the normative power of this argument depends on the impact of parental incarceration on children's interests. If parental incarceration would (in general) have either positive or at least no negative consequences on children, the status of parenthood would have a different effect on the prima facie rule that mothers should be treated differently than if there would be evidence of negative consequences. A second premise that underlies the principle of differential treatment of mothers is that these mothers actually serve the interests of their children. Whether or not this can be defended will be discussed in the next section. First, we will turn to the empirical research into the consequences of imprisonment of mothers on their children.

\subsection{Prevalence}

The number of detainees in Western countries has increased tremendously over the past decades (Tonry \& Bijleveld, 2007; Scharff-Smith \& Gampell, 2011). This has led to a corresponding increase in the number of children with an incarcerated parent. In the United States, over 50\% of prisoners reported having a child under the age of 18 (Western \& Pettit, 2010). For the Netherlands, it has been estimated that about half of detained women have underage children (Slotboom, et al., 2008); data for detained men are unavailable. According to Glaze and Maruschak (2010), parents held in U.S. prisons had an estimated 1,706,600 children in 2007, which equals $2,3 \%$ of the nation's minors, a rise of almost $50 \%$ since 1991 (945,600 children). Although most incarcerated parents are fathers, the number of children with an imprisoned mother has grown faster $(131 \%)$ than children with an imprisoned father (77\%) since 1991 (Glaze \& Maruschak, 2010). For the Netherlands, a western European country with little less than 17 million inhabitants and an incarceration rate slightly above the European average (Note 4) but still much lower than the US rate, the number of incarcerated women doubled from 400 in 1995 to about 800 in 2005, back to about 700 per day in 2009 (average per day). This is also a much steeper increase than the rise in the number of male detainees, which was around 60\% until 2005 (Slotboom, Bijleveld, Day and Van Giezen, 2008). It is as yet unclear to what this sharper rise of detained females can be ascribed. For the Netherlands, part of the rise is in all likelihood attributable to long sentences for female drug mules. However, as the increase is observed in several Western countries, other factors probably play a role as well.

\subsection{Effects of Detention}

U.S. as well as European studies have shown that the children of incarcerated mothers are prone to experience a multitude of problems. These children have elevated levels of externalizing problems, with antisocial behavior, delinquency, drug use and school drop-out as possible outcomes (Murray and Farrington, 2008; Tasca et al., 2011). The percentages of children for whom externalizing problem behavior was found, however, varies from 10-30\% across studies (for instance, Johnston, 1991, 1995; Myers et al., 1999; Tasca et al., 2011; Trice, 1997). This discrepancy may be related to the country in which the research has been performed. Research has shown that negative outcomes such as delinquency and convictions are likely to vary due to differences in stigma of imprisonment and access to prisoners in various countries (Besemer et al., 2011; Murray, Janson, \& Farrington, 2007). Increased levels of internalizing problems, like depression complaints, anxiety and emotional problems, substance abuse, sleep problems and reduced concentration of children have also been reported (Note 5) (Johnston, 1995; Myers et al., 1999; Murray, 2005; Murray \& Farrington, 2008; Poehlmann, 2005).

Recently, empirical research amongst imprisoned mothers and their children was performed in the Netherlands (Hissel, Bijleveld, \& Kruttschnitt, 2011). This study aimed to assess the impact of maternal incarceration on children in the Netherlands, a country where sentences are relatively short and that has a strong social security support net. This research has two important merits. Firstly, unlike most previous research, both the incarcerated mothers and her children as well as the current caregivers of these children were interviewed about the impact of the mothers' imprisonment. Secondly, the Child Behavior Checklist was completed by both mothers and temporary caregivers and resulting scores on internalizing and externalizing behavior problems were gauged against norm scores.

Mothers and caregivers reported substantively elevated external as well as internal behavioral problems in their children as compared to a norm group of the same age and gender. The valid norm is that $7 \%$ of the norm group has a problem (borderline or clinical) score on the internalizing, the externalizing and the total problem behavior scale, measured by the CBCL. A problem score on the total scale of problem behavior was reported for $32 \%$ of the children by the mothers and for $55 \%$ of the children by the caregivers. Internalizing problem behavior was 
reported for $47 \%$ (reported by mothers) and 50\% (reported by caregivers) of children, with affective problem behavior being mentioned most often. Externalizing problem behavior was reported for $26 \%$ (reported by mothers) and $36 \%$ (reported by caregivers) of children.

The study also revealed that apart from universal grief of having a detained mother (see also Braam, Mak and Tan, 2007); there was considerable variation in how children responded to their mother's incarceration. Children, as well as mothers and caregivers, indicated that maintaining contact was difficult and often charged. On average, in younger children, sadness and 'missing mum' prevailed. Almost all younger children wanted to be reunited with their mother as soon as possible. In older children, reactions were more nuanced. Older children were much more afraid of bullying (Note 6) and many of them kept silent to the outside world about the reason of their mother's absence, informing only a limited group of relatives and friends about their mother's detention. Some even experienced relief, reporting that now their mother was safe, could get off drugs, think over her mistakes, and/or that mother's detention gave them some breathing space. In some cases, the detention of the mother had improved the relationship and mutual concern between mother and child.

While empirical research has consistently indicated that detention of mothers has a negative effect on children, it is notoriously hard to determine if the consequences can be attributed to parental imprisonment. Studies in different countries have all indicated that many risk factors in these children were already present prior to their mother's incarceration, such as neglect and abuse, an antisocial environment, unemployment and poverty, as well as problematic parenting styles (Ezinga \& Hissel, 2010; Murray \& Farrington, 2005; Dodd \& Hunter, 1992; Singleton et al., 1998). Proving that the problems that children face can be exclusively contributed to maternal imprisonment is almost impossible for several reasons: a) detention is not imposed at random, b) children of incarcerated mothers grow up in a context of frequent care giving disruptions (Phillips et al., 2006), c) children are at elevated levels of exposure to risk factors such as poverty, neglect and child abuse (Phillips et al., 2002), and d) family instability (Tasca et al., 2011) as well as other types of burdens to the family (drug abuse, violence, unemployment, divorce). Problems may incur from the incarceration, but also its corollaries, like trauma from witnessing the arrest, separation from the mother or the realization that the mother is a criminal (Arditti et al., 2003; Murray \& Farrington, 2008), as well as negative influences of the social environment, like stigmatizing, social exclusion and bullying (Boswell \& Wedge, 2002; Codd, 1998; Murray, 2005; Murray \& Farrington, 2008) Findings from qualitative studies show overwhelming support for this conclusion. Thus, it is important that more and particularly longitudinal research is instigated to study the negative (and possibly for some children positive) effects of parental incarceration on children's lives.

Although we cannot be certain that imprisonment of mothers is the only or primary cause of the problems of children, we argue that the interests of children are too important to rest our case at that. The added risk and suffering of children on top of the many adverse circumstances that were just mentioned justify the principle of alternative sentencing: harm to children, who are innocent, by the legal system should be prevented as much as possible. However, even if this is accepted, the effect of maternal imprisonment is only part of the justification of alternative sentencing. The justification also requires that mothers are indeed able to serve the interests of their children. This question requires empirical research as well as theoretical reflection. It is the latter that we set out to do in the next section.

\section{Can Mothers Who Are Sentenced to Prison Serve the Interests of Their Children?}

Normally, parents feel morally responsible for the well-being of their offspring and therefore refrain from acting in ways that endanger their children's (long term) interests. Roughly, the interests of that parents need to serve can be clustered into basic needs that all human beings have, but for which children are dependent on adults (for instance food, shelter, clothing, but also freedom), and interests that are particular to children (having an adult who loves them unconditionally and who assists them in their physical, emotional, cognitive, social development and who gives them freedom to develop themselves). Obviously, a prison sentence given to mothers who are also principal caregivers diminishes their possibility to serve these interests of children. Particularly the interest of children to be raised by an adult who unconditionally loves her child and who is dedicated to serving her child's developmental interests is being harmed. While other adults can attend to many basic interests of children and their development interests too, the interest of children to be raised by their own parent is infringed.

This means that mothers can be said to have an additional reason for abstaining from committing criminal acts next to the moral reasons that all adults are expected to have - namely that doing so threatens their children's interests. If mothers love and care for their children, they would not commit a criminal offence, because they know that a punishment will affect their children's interests. On the basis of this premise and arguments it could be concluded that if mothers do commit a crime, their parental status does not justify differential treatment, 
because they have annulled the grounds for applying this status by acting against the best interests of their children.

Is this a valid argument? The principle of justice requires that treating person $A$ differently from $B$ cannot be based on reasons that $A$ could have known, should have borne in mind, was able to act upon and if there were no overriding alternative reasons that justified A's behavior. For instance, it is thought to be fair that everyone receives the same fine for speeding on the basis of the idea that everyone knows the maximum speed limit, unless there are mitigating circumstances. This seems to apply to the situation of mothers who commit a crime too. We do not seem to have good reasons to sentence mothers differently on the basis of the interests of children, because they could and should have known what those interests are and therefore could have avoided damaging them. Even if mothers were breaking the law with the intention to benefit their children, it can still be argued that they endangered the interest of their child to be cared for and raised by their own mother (see also Markel, Collins, \& Leib 2007; Markel, Collins, \& Leib, 2009). Therefore, drawing on the interests of children to be raised by their mothers and to maintain an intimate relationship with them seems to be counterintuitive, because the persons who are treated differently are the ones that should have served these interests. This argument is correct, but not sufficient for changing the principle. Instead of looking at the mother who is responsible for her deeds, we can also focus on children who are dependent on their mother and who are innocent. The fact that mothers did not abstain from actions that they could have known to be detrimental to their children's interest does not necessarily imply that the sentencing should not take into account these interests either. The interests of children have not disappeared or diminished and therefore can still be grounds for alternative sentencing.

This perspective zooms in on the caregiving relationship. It argues that alternative sentencing is (still) justified if mothers who were (involved in) raising their children up to the moment of their detention are able to provide a safe and caring environment. While it may be argued that mothers who committed a crime have therefore disregarded the interests of their children, it is possible that they are still good (enough) mothers. There are, to our knowledge, no empirical data available that can help us in substantiating this position and therefore we do not know how many mothers are able to provide such an environment, and to raise and educate their children (Note 7). However, as ample examples show, raising one's children requires capacities and attitudes that are not incompatible with committing heinous crimes. A committed felon does not necessarily lack the qualities that are necessary for being a good enough parent.

We seem to have found a ground for treating mothers differently, even though they have damaged the children's interests by committing a crime: if they sufficiently cared for their children, the balance of meeting their children's interests tips to the positive side. One might object to our line of reasoning with the following argument: it may be true that criminal mothers are able to assist their children with most of their developmental tasks, but it is highly questionable if they provide sufficient support for the moral development of their children. Even if mothers educate their children to abide the minimal or basic moral rules of society that are laid down in the laws of the country, offending mothers do not set a good enough moral example for their children. The role models that such mothers provide actually seem to undermine whatever moral education they provide. This is true at face value, but depends on other factors as well, for instance on the feelings of guilt and shame mothers may have and expose. The fact that they have committed an immoral act does not necessarily make them immoral persons. This is dependent on their attitudes with regard to their own behavior and their moral emotions.

All in all, we conclude that although there seem to be strong arguments against the principle of alternative sentencing, they are not sufficient to undermine it.

\section{The Special Status of Children's Interests}

We have given various arguments why consideration of the interests of children should lead to the differential treatment of mothers. Differential treatment of defendants that is not based on the mental state of the defendant and does not pertain to the crime is obviously highly problematic.

We want to stress that we do not defend the view that criminal mothers do not have to be tried or sentenced; they are blameworthy like any other perpetrator. We do not want to abandon the principle of punishment or the principle of retribution. However, since imprisonment of the mother harbors the risk of collateral damage to the well-being of children that can be avoided, retributive measures directed at the mothers should, if possible, take other forms. What type of alternative punishment is comparable to a prison sentence is not the concern of this article. In order to be able to justify differential treatment it is however necessary to establish that there are alternative sentences that are of equal severity as imprisonment that can - or as we suggest, should - be sought as replacement. To this we return at the end of the article. 
But why would the interests of children have such a special force? A utilitarian argument, drawing on the well-being or interests of those affected as we do, takes into account the interests of all parties involved, i.e. the victims too, and why would the interests of one of the parties be given greater importance than those of others? For this, we turn to the UN Convention on the Rights of the Child. This convention gives us reason to believe that children's interests do have special force.

Three articles could be interpreted as grounds for the state to treat mothers differently when it comes to imprisonment (Note 8). According to articles 5, 18.1 and 27.2 of the convention, parents have the primary responsibility to look after their children. The state not only has the duty to respect the responsibilities, rights and duties of parents to care for their children, but also "to ensure recognition of the principle that both parents have common responsibilities for the upbringing and development of the child" (article 18.1). Moreover, according to article 3.1 "In all actions concerning children, whether undertaken by public or private social welfare institutions, courts of law, administrative authorities or legislative bodies, the best interests of the child shall be a primary consideration".

An interesting question for our topic is how one may interpret 'concerning children' in article 3.1. While we recognize that imprisonment of mothers is an action of the state against mothers and that the article has to be interpreted in conjunction with other articles of the CRC, the article does allow for an interpretation of state action that indirectly concerns children (see also Boudin, 2011). For, 'concerning children' may also mean 'in relation to' or 'in connection with' or 'pertaining to' and following these meanings, the article also applies to situations of the imprisonment of mothers, because this action of the state affects (the interests of) children. Therefore, it can be argued that the International Convention minimally gives states room to consider the possibility of differential treatment of mothers. This is similar to the view of Marshall, the former children's rights commissioner of Scotland, who argues: 'This means that, when courts are considering imposing sentences on parents that will impact upon children, they must refer to, and take account of, the best interests of the children affected. It does not mean that the impact on the children must be the decisive consideration. ( .....) But it does insist that serious consideration, and serious weight, be given to the rights of the children' (2008, p. 9).

We agree with Marshall that children's rights are not absolute, which is why we have called the principle a prima facie principle. However, we do defend a stronger position than Marshall, arguing that the state should begin with the assumption that it has to ensure the rights of children, which also means that mothers should receive alternative sentencing if it is in the children's interest to maintain the relationship with their mother and to have direct contact with her. Given that in most countries the number of women's prisons is quite low and spread throughout the country, this direct contact is best met when mothers are not imprisoned.

However, as said, our defense should not only take into account the interests of children, but also those of other parties involved. The literature mentions another danger (for instance Boudin, 2011; Markel et al., 2007, 2009), namely that treating mothers differently may increase the number of victims, because it may actually form an incentive to criminal behavior. The idea is that if women learn that being a mother means that they have a chance of avoiding imprisonment, they will be less reluctant to break the law. While Markel, Collins and Leib (2007; 2009) acknowledge that there is no empirical evidence to substantiate this premise, there are other reasons for believing that this argument does not undermine our principle of alternative sentencing. Firstly, as said, we do not propose that mothers should receive a lesser sentence, but a different or differently timed one. Secondly, if women would become mothers in order to avoid a prison sentence or if mothers would use their position as an excuse to become criminally active, we may have substantial reasons to presume that they are not good enough caregivers. Apart from the fact that bringing a child into the world in order to avoid imprisonment seems quite bizarre, these mothers and the mothers who believe that their status gives them the possibility to pursue a criminal career without the detrimental consequences are clear instances in which mothers use their children as a means only instead of seeing them as an end in themselves. In other words, they intentionally use their child to be able to avoid particular consequences of their acts. If mothers do think and act along these lines, the question arises as to whether they normally put their child's interests ahead or equal to their own, in other words whether or not they have the basic moral qualities to be a good enough mother to their child. Although empirical evidence is not available, it is intuitively plausible to assume that this will lead to a negative answer. Thus, it is likely that such mothers will not be treated differently, which immediately diminishes the possible incentive.

Secondly there might be deleterious consequences in the practice of applying our proposal for young women or mothers. Others than the future mothers themselves may have immoral motives and force young mothers to commit criminal offences. However, we have argued that mothers would still have to serve some sentence. Moreover, in this case mothers could claim duress, and the instigator would, if this were accepted, be fully accountable under criminal law. This makes such use of mothers hardly a profitable route for those third parties. 
Finally, although we believe that the interests of children are sufficient for defending an alternative sentence for mothers, our utilitarian defense could also include the positive consequences for society. As shown in the second section, children of imprisoned mothers have significantly more externalizing and internalizing problems. These have an effect on society at large. These children may be less able to contribute to the welfare of a society and ongoing externalizing problem behavior clearly has negative impacts on society too. Thus, the well-being of society at large may benefit from differential treatment as well. Obviously this argument hinges on empirical premises that have not been researched, for instance if children whose mother is given an alternative sentence rather than imprisonment have fewer problems. Conversely, negative consequences for society also have to be taken into account. A decision to offer mothers an alternative to a prison sentence can only be justified if the legal order and the interests of society and its citizens are not disproportionally threatened. Some crimes may be too serious, or some mothers may pose too great a threat to society (or their children) to allow for alternative sentencing.

\section{In Conclusion and Some Reflections on Practical Implications}

We conclude that the interests of children can be a reason for non-imprisonment of mothers. This conclusion does not mean that mothers should not be sentenced for the criminal offence they have committed. We have 'only' argued that if a mother was raising her children up to the arrest, if there are no reasons to assume that she would not be able to continue to provide a stable and safe environment for her children, the judge should in principle consider an alternative to immediate imprisonment. Interestingly, this is not a novel proposal. The African Charter on the Rights and Welfare of the Child, that was drawn up in 1990 and ratified by sufficient countries in 1999, also states that mothers have to be treated differently (Note 9).

Our focus has been specifically on mothers who raise their children until the moment they are convicted. We have assumed that there is no father who has an equal share in the upbringing of children and who would be able and willing to raise the children on his own while the mother is imprisoned. In situations where the father has such a role, the grounds for our proposal to treat mothers differently are weakened, because in those situations the father can be the continuing caregiver and attachment figure. Whether or not that is the case indeed, must be investigated in each situation, for decisions in such instances will depend on the particular roles and positions of the mother and father. We have also assumed that the situation in which children are raised by a single mother is more common than one in which the father is the single caregiver, but obviously, the principle equally applies to single fathers who raise their children.

As we have stated in the introduction, this is a theoretical article defending a principle of alternative sentencing of mothers. However, we want to end with a few reflections on the practical implication of this principle. These are again based on the basis of our principle, i.e. the interests of children. The main thrust of our reflection is therefore that these interests should also be leading in deciding what needs to happen when a mother is convicted. In general, the principle of alternative sentencing will lead to more involvement of social services with the family (see also Flynn, 2013).

First of all, judges need to have insight into the family situation to be (relatively) certain that the mother indeed serves her children's needs and interests. The judge can request a social worker to investigate the circumstances in which the children live, the quality of the relationship between the mother and her children, the (psychological) problems of the mother and the children in order to draw up a conclusion if the situation at home is sufficiently safe and nourishing. We do suggest, however, that this investigation begins with the assumption that the mothers are good enough parents. Only in situations in which there are sufficient indications that the interests of children are not being met by the mother, should child protection services be asked to thoroughly investigate family circumstances. The reason for this rule is also based on the children's interests. An investigation by the child protection service is intrusive and is normally only requested by the judge if there are signs that the parents do not provide adequate care. We also want to stress that it is important that children are heard too. Interviewing the children is, however, highly sensitive in this case and will require specific skills of a social worker; it is important to prevent that children feel burdened with the responsibility that they can prevent (or cause) imprisonment of their mother.

Secondly, children's interests warrant that a social worker is assigned to the family. It is possible that mothers voluntarily ask for support, for instance because their contact with the legal system has lowered the threshold to have outsiders involved in their family life. But if they do not, the judge should order that a specifically trained social worker assists the family in coping with the alternative sentence of the mother, to prevent mother from committing another crime, and monitor the well-being of the children. We want to stress that this does not imply a child protection measurement. The social worker we envisage assisting the family does not have legal authority 
over the children. It is, however, important that the mother and children have a source of professional support who can guide them and who is able to refer them to other professionals whom the mother or children may need. For, as we have written in the second section, it is quite likely that there are adverse circumstances which the sentencing may aggravate. A social worker can help to ensure that the alternative sentencing will be successful.

If mothers refuse the assistance that the child protection service or social worker deems necessary this still does not have to imply that children be placed in (foster) care and that mothers be imprisoned. Children are not necessarily removed from their homes when they are placed under supervision. Again, we suggest that in cases in which the supervision measure would normally not lead to removal of children from their parents there are no reasons why the legal and welfare system treat criminal mothers and their children differently.

Thirdly, which type of alternative sentencing should be given to the mother has to be decided in each individual case. This is obviously determined by the crime the mother has committed, but also has to take into account the effect on the children. This will depend on the age of the children and their relation to their mother - remember that the empirical research conducted in the Netherlands we described in the second section also showed that for some (especially older) children their mother's prison sentence was a relief. It is true that not all crimes a mother commits allow for alternative sentencing, particularly those in which the children were involved or in case of severe neglect or abuse. However, we suggest that in case of offences like theft or fraud, the judge should consider alternative sentencing. Community service, electronic detention or daytime detention are examples, which seem to be good alternatives where mothers can look after their children and serve their sentence at the same time. Other modes could be explored too, such as delaying the detention until after the children have turned 18 (see also Markel et al., 2007, 2009).

We are unaware of any empirical research into the impact of types of alternative sentences of mothers on children. In general, we do not seem to need empirical evidence to suggest that the less intrusive the alternative sentence, the lower the likelihood that it will harm children, although this will depend on various other factors too like the resilience of children and the personal problems of the mother. Daytime detention or community service seems to be particularly apt when children are still young; postponement may be an option only when children have reached the age of adolescence. Of course, options for alternative sentences depend on practicalities too. For instance, not all families live close to a prison where mothers can be confined during the day, neither is community service available in every situation. But practicalities can be solved and new types of alternative sentences can be developed. In our opinion the interests of children are sufficient to justify investment in building day prisons or developing schemes for community service, but it may even be expected that they are cost effective in the end, because children's well-being is less affected or not harmed.

We end with a call for further empirical research into the consequences of alternative sentencing of mothers (and fathers) who are primary caregivers. This article has given normative theoretical reasons why the principle of alternative sentencing is justified. Now we need further insight into the practice of applying this principle. In order to do so it is of course necessary that the principle be applied. We hope this will be the case (Note 10) sooner rather than later.

\section{References}

Arditti, J. A., Lambert-Shute, J., \& Joest, K. (2003). Saturday morning at the jail: Implications of incarceration $\begin{array}{llll}\text { for families and children. Family } & \text { Relations, }\end{array}$ http://dx.doi.org/10.1111/j.1741-3729.2003.00195.x

Besemer, S., van der Geest, V., Murray, J., Bijleveld, C. C. J. H., \& Farrington, D. P. (2011). The Relationship between Parental Imprisonment and Offspring Offending in England and the Netherlands. British Journal of Criminology. http://dx.doi.org/10.1093/ bjc/azq072.

Bloom, B. (1993). Incarcerated mothers and their children: Maintaining family ties. In Female offenders: Meeting needs of a neglected population. Laurel, MD: American Correctional Association.

Boswell, G., \& Wedge. P. (2002). Imprisoned fathers and their children. London: Jessica Kingsley.

Boudin, C. (2011). Children of incarcerated parents: The child's constitutional right to the family relationship. The Journal of Criminal Law and Criminology, 101(1), 77-118.

Braam, H., Mak, J., \& Tan, S. (2007). Moeders in detentie en de omgang met hun kinderen. Utrecht: Verwey-Jonker Instituut.

Codd, H. (1998). Prisoners' families: the 'forgotten victims'. Probation Journal, 45(3), 148-54. http://dx.doi.org/10.1177/026455059804500305 
Dodd, T., \& Hunter, P. (1992). The National Prison Survey 1991: A report to the Home Office of a study of prisoners in England and Wales carried out by the Social Survey Division of OPCS. London: HMSO.

Ezinga, M., \& Hissel, S. (2010). Kinderen van gedetineerde moeders: Een studie naar het gedrag en welbevinden van kinderen met een moeder in de gevangenis. Tijdschrift voor Criminologie, 52(1), 36-51.

Fishman, S. H. (1983). Impact of incarceration on children of offenders. Journal of Children in Contemporary Society, 15, 89-99. http://dx.doi.org/10.1300/J274v15n01_11

Flynn, C. (2013). Mothers Facing Imprisonment: Arranging Care for Their Adolescent Children. Women \& Criminal Justice, 23(1), 43-62. http://dx.doi.org/10.1080/08974454.2013.743372

Glaze, L. E., \& Maruschak, L. M. (2010). Parents in prison and their minor children. Washington, DC: Bureau of Justice Statistics.

Hissel, S., Bijleveld, C., \& Kruttschnitt, C. (2011). The well-being of children of incarcerated mothers: An exploratory study for the Netherlands. European Journal of Criminology, 8, 246-360. http://dx.doi.org/10.1177/1477370811415755

Huebner, B. M., \& Gustafson, R. (2007). The effect of maternal incarceration on adult offspring involvement in the criminal justice system. Journal of Criminal Justice, 35, 283-296. http://dx.doi.org/10.1016/j.jcrimjus.2007.03.005

Johnston, D. (1991). Jailed mothers. Pasadena, CA: Pacific Oaks Center for Children of Incarcerated Parents.

Johnston, D. (1995). Effects of parental incarceration. In K. Gabel, \& D. Johnston (Eds.), Children of incarcerated parents. New York: Lexington Books.

Markel, D., Collins, J. M., \& Leib, E. J. (2007). Criminal justice and the challenge of family ties. University of Illinois Law Review, 4, 1147-1127.

Markel, D., Collins, J. M., \& Leib, E. J. (2009). Privilege or punish. Criminal justice and the challenge of family ties. Oxford: Oxford University Press. http://dx.doi.org/10.1093/acprof:oso/9780195380064.001.0001

Marshall, K. (2008). Not seen. Not heard. Not guilty. The rights and status of children of prisoners in Scotland. Edinburgh: SCCYP. Retrieved from http://www.crin.org/docs/ notseen.pdf

Murray, J. (2005). The Effects of imprisonment on families and children of prisoners. In A. Liebling, \& M. Shadd (Eds.), The Effects of Imprisonment. Portland, Oregon: Willan Publishing.

Murray, J., \& Farrington, D. P. (2005). Parental imprisonment: effects on boys' antisocial behaviour and delinquency through the life-course. Journal of Child Psychology and Psychiatry, 46, 1269-1278. http://dx.doi.org/10.1111/j.1469-7610.2005.01433.x

Murray, J., \& Farrington, D. P. (2008). Parental imprisonment: Long-lasting effects on boys' internalizing problems through the life-course. Development and Psychopathology, 20(1), 273-290. http://dx.doi.org/10.1017/S0954579408000138

Murray, J., Farrington, D. P., Sekol, I., \& Olsen, R. F. (2009). Effects of parental imprisonment on child antisocial behaviour and mental health: A systematic review. Oslo: The Campbell Collaboration. http://dx.doi.org/10.4073/csr.2009.4

Murray, J., Janson C. G., \& Farrington, D. P. (2007). Crime in adult offspring of prisoners: A cross-national comparison of two longitudinal samples. Criminal Justice and Behavior, 34(1), 133-149. http://dx.doi.org/10.1177/0093854806289549

Myers, B. J., Smarsh, T. M., Amlund-Hagen, K., \& Kennon, S. (1999). Children of incarcerated mothers. Journal of Child and Family Studies, 8(1), 11-25. http://dx.doi.org/10.1023/A:1022990410036

Phillips, S. D., Burns, B. J., Wagner, H. R., Kramer, T. L., \& Robbins, J. M. (2002). Parental incarceration among youth receiving mental health services. Journal of Child and Family Studies, 11(4), 385-99. http://dx.doi.org/10.1023/A:1020975106679

Phillips, S. D., Erkanli, A., Keeler, G. P., Costello, E. J., \& Angold, A. (2006). Disentangling the risks: Parent criminal justice involvement and children's exposure to family risks. Criminology and Public Policy, 5(4), 677-702. http://dx.doi.org/10.1111/j.1745-9133.2006.00404.x

Poehlmann, J. (2005). Incarcerated mother's contact with children, perceived family relationships, and $\begin{array}{llll}\text { depressive symptoms. Journal of Family Psychology, 19(3), 350-357. } & \text {. }\end{array}$ http://dx.doi.org/10.1037/0893-3200.19.3.350 
Schafer, N. E., \& Dellinger, A. B. (1999). Jailed parents: An assessment. Women \& Criminal Justice, 10(4), 73-91. http://dx.doi.org/10.1300/J012v10n04_04

Scharff-Smith, P., \& Gampell, L. (Eds.) (2011). Children of imprisoned parents. The Danish Institute for Human Rights, European Network for Children of Imprisoned Parents, University of Ulster and Bambinisenzasbarre.

Singleton, N., Meltzer, H., Gatward, R., Coid, J., \& Deasy, D. (1998). Psychiatric morbidity among prisoners. London: Stationery Office.

Slotboom, A. M., Bijleveld, C. C. J. H., Day, S. N., \& Van Giezen, A. E. (2008). Gedetineerde vrouwen in Nederland. Amsterdam: Vrije Universiteit.

Tasca, M., Rodriguez, N., \& Zatz, M. S. (2011). Family and residential instability in the context of paternal and maternal incarceration. Criminal Justice and Behavior, 38, 231-247.

Tonry, M., \& Bijleveld, C. C. J. H. (Eds.) (2007). Crime and justice in the Netherlands (Vol. 35). Chicago: The University of Chicago press.

Travis, J. (2005). Families and children. Federal Probation, 69 (1), 31-42.

Van Nijnatten, C. (1998). Detention and development. Perspectives of children of prisoners. Mönchengladbach: Forum Verlag Godesberg.

Western, B., \& Pettit, B. (2010). Incarceration and social inequality. Daedalus, 139(3), 5-7. http://dx.doi.org/10.1162/DAED_a_00019

\section{Notes}

Note 1. This is true for the US (Glase and Maruschak, 2010); for European countries it is more difficult to provide such data due to prison registration system in most countries (see Scharff-Smith and Gampell, 2011).

Note 2. Although Glaze and Maruschak also report that 'fewer than half of parents in state prison lived with their minor children either in the month before arrest or just prior to incarceration' (2010, p. 4).

Note 3. In the remainder of the article we will only use 'mothers' as they form the most important group of persons whose imprisonment has great impact on children, but this stands for all active primary caregivers.

Note 4. European average in 2007 was 4,5-5\%, while in the Netherlands it was over 7\% (Scharff-Smith and Gampell, 2011).

Note 5. There are no figures available on the size of the increase.

Note 6. Van Nijnatten (1998) also reports feelings of shame and guilt.

Note 7. Estimates obviously also depend on what is understood by a safe and educative environment - the stricter or more encompassing the concept is interpreted, the smaller the group will be. However, it seems reasonable to apply the criteria that are described in national laws with regard to state intervention in families. In Western countries, these criteria are minimal in character, for it is characteristic for liberal democratic states to be reluctant to interfere in family life.

Note 8 . Article 9 states that if one or both parents are detained or imprisoned by the state, the child should be informed about the whereabouts of their parents, unless it is detrimental to their well-being (section 4), and children have the right to maintain a personal relation and direct contact with both parents on a regular basis unless it is contrary to their interests. This article, which is the only one that specifically addresses the detention of mothers, indicates that mothers can be treated differently than other female prisoners to ensure that the right of the child to maintain the relationship with their mother and to have direct contact is being met. This could for instance be accomplished by allowing babies and toddlers to stay with their mothers in prison or by expanding the visiting hours for children. However, the article does not indicate that this different kind of treatment extends to non-detention of mothers.

Note 9. Article 30: Children of Imprisoned Mothers reads:

1. States Parties to the present Charter shall undertake to provide special treatment to expectant mothers and to mothers of infants and young children who have been accused or found guilty of infringing the penal law and shall in particular:

(a) ensure that a non-custodial sentence will always be first considered when sentencing such mothers; 
(b) establish and promote measures alternative to institutional confinement for the treatment of such mothers;

(c) establish special alternative institutions for holding such mothers;

(d) ensure that a mother shall not be imprisoned with her child;

(e) ensure that a death sentence shall not be imposed on such mothers;

(f) the essential aim of the penitentiary system will be the reformation, the integration of the mother to the family and social rehabilitation.

Note 10. As we have stated in the beginning, we have not investigated legal systems nor did we want to discuss the impact of our principle on the legal system of specific countries. It is, however, clear that in countries in which there is a minimum mandatory sentencing like in the US and the UK, our principle of alternative sentencing requires a profound legal change if there are situations in which the law necessitates detention while the interests of the children demand alternative sentencing. How these changes be made effective will be different in each country or even in each State in the US.

\section{Copyrights}

Copyright for this article is retained by the author(s), with first publication rights granted to the journal.

This is an open-access article distributed under the terms and conditions of the Creative Commons Attribution license (http://creativecommons.org/licenses/by/3.0/). 